\title{
EMPREGO DA TÉCNICA DE HRGC NA IDENTIFICAÇÃO DA ISOTRETINOÍNA E SEUS PRODUTOS DE DEGRADAÇÃO EM MEDICAMENTOS
}

\author{
Use of HRGC for the identification of Isotretinoin and its degradation products in \\ pharmaceuticals
}

\author{
Danielle G. A. Diniz ${ }^{1}$; Carina P. I. Alves ${ }^{2}$; Eliana M. Lima ${ }^{3^{*}}$; Nelson R. A. Filho ${ }^{4}$. \\ ${ }^{1}$ Professora Assistente da Faculdade de Farmácia/ UFG; doutoranda em Ciências da Saúde (UFG/UnB); \\ ${ }^{2}$ Mestranda em Ciências da Saúde (UFG/UnB); \\ ${ }^{3}$ Professora Doutora da Faculdade de Farmácia / UFG e Coordenadora do Laboratório de Tecnologia \\ Farmacêutica/ FF; \\ ${ }^{4}$ Professor Doutor do Instituto de Química da UFG e Coordenador do Laboratório de Métodos de Extração e \\ Separação / IQ.
}

* Autor para correspondência. emlima@farmacia.ufg.br

Recebido em 28/09/2004 - Aceito em 19/12/2004

\begin{abstract}
RESUMO: A isotretinoína, quimicamente conhecida como ácido -13-cis-retinóico, faz parte do amplo grupo de compostos relacionados à vitamina $A$. É empregada particularmente no tratamento da acne cística e nodular e como inibidor da proliferação de células neoplásicas, por exercer efeito regulador sobre a diferenciação celular. Este artigo descreve o emprego do método de cromatografia gasosa de alta resolução na identificação e separação da isotretinoína e seus produtos de degradação em preparações farmacêuticas. Os resultados demonstraram a grande eficiência deste método para avaliação da qualidade, tanto da matéria prima, como das formas farmacêuticas disponíveis no mercado.
\end{abstract}

PALAVRAS CHAVE: HRGC, Isotretinoína, produtos de degradação, Medicamentos.

ABSTRACT: Isotretinoin or 13-cis-retinoic acid is a member of the large group of Vitamin A related compounds. Due to its effect on regulating cell differentiation it has been used for the treatment of cystic and nodular acne and also as an inhibitor of neoplasic cells proliferation. This paper describes a gas chromatography method used for the assay of isotretinoin in its isolated form and in pharmaceutical formulations. Results showed that the method exhibited a high efficiency to determine the quality of isotretinoin in raw materials and in pharmaceuticals.

KEYWORDS: HRGC, Isotretinoin, degradation products, pharmaceuticals

\section{INTRODUÇÃO}

A isotretinoína (ácido 13-cis-retinóico) é um derivado da vitamina A particularmente empregada no tratamento da acne cística e nodular e na prevenção de lesões neoplásicas principalmente do sistema hematopoiético, por apresentar grande eficiência na regulação da diferenciação celular. Os efeitos adversos envolvendo o uso de isotretinoína estão relacionados à pele e membranas mucosas, sistemas nervoso, músculo esquelético, linfático, gastrintestinal, cardiorespiratório e geniturinário. [SPORN, et al. 1976; HARISIADIS, et al. 1978; LOTAN, 1980; LOTAN, et al. 1980; BREITMAN, et al. 1981;SPORN, ROBERTS, 1985; NAGPAL, et al. 1995; CHANDRARATNA, 1996; ELLIS,et al 2001; DINIZ, et al 2002].

A isotretinoína é comercializada no mercado brasileiro como medicamento de marca registrada, similar e genérico sob a forma farmacêutica de cápsulas de gelatina mole nas concentrações de 10,20 e $40 \mathrm{mg}$, e também 
sob a forma de cápsulas de gelatina dura manipuladas em farmácia e adequadas à posologia prescrita pelo médico. [ANVISA, 2003; FDA, 2002]. Devido à fotolabilidade, à sensibilidade ao calor e à oxidação dos retinóides, sua determinação quantitativa em formas farmacêuticas é particularmente importante para o controle de qualidade do produto final e para os ensaios indicativos de estabilidade [GATTI, et al. 2000].

A cromatografia sempre representou a técnica analítica preferida para a análise dos retinóides e a cromatografia líquida de alta eficiência (HPLC) tornou-se, paulatinamente, o método analítico predominante para a separação e quantificação dos retinóides, tanto em amostras biológicas quanto em formas farmacêuticas. Ao todo, há um vasto número de retinóides naturais e sintéticos com diferentes polaridades e o desenvolvimento de um método analítico que possa separar todos os retinóides em somente uma análise cromatográfica tem demonstrado ser uma tarefa muito difícil. Deste modo, as condições cromatográficas são muitas vezes elaboradas para cada aplicação analítica pretendida [GUNDERSEN, et al. 1997; GUNDERSEN, BLOMHOFF, 2001].

Chiang (1980) determinou os níveis de ácido retinóico em sangue humano por cromatografia gasosa acoplada a detectores de massas (GC-MS), Oyler e colaboradores (1989), Lehman e Malany (1989) e Eckhoff e Nau (1990) conseguiram caracterizar a isotretinoína e seus produtos de degradação em amostras biológicas empregando GC.

Lehman e Malany (1989) empregaram GC-MS para comprovar os picos de eluição designados para a isotretinoína e tretinoína por HPLC. Todas as amostras demonstraram correspondência com os tempos de eluição obtidos por GC e HPLC. Eckhoff e Nau (1990) investigaram a presença endógena dos ácidos todo-trans e 13-cisretinóico e dos ácidos todo-trans-4-oxo-retinóico e 13-cis-4-oxo-retinóico no plasma humano empregando três sistemas analíticos de HPLC e um sistema GC-MS-SIM (cromatografia gasosa acoplada a espectrometria de massas no modo de monitoramento de íons selecionados).

Embora a cromatografia gasosa tenha sido aplicada na determinação da isotretinoína em amostras biológicas, seu emprego na avaliação de medicamentos ainda carece de maiores investigações. Neste trabalho foi empregada a técnica de HRGC para identificação da isotretinoína e seus produtos de degradação em diversas formas farmacêuticas, desde a matéria-prima aos produtos acabados disponíveis no mercado nacional.

\section{MATERIAL E MÉTODOS}

\section{Reagentes}

Foram analisadas as seguintes amostras de isotretinoína: padrão USP 353500, matéria-prima (GALENA), medicamento de marca, genérico e cápsulas de gelatina dura manipuladas em farmácia. As amostras foram preparadas em diclorometano grau UV-HPLC. Foram utilizados gases especiais para cromatografia gasosa e todos os demais reagentes eram de grau analítico.

\section{Sistema Cromatográfico}

As análises foram realizadas em equipamento Agilent 6890 System Plus, em coluna 007-65 HT (15m $\mathrm{x}$ $0,18 \mathrm{~mm} \times 0,1 \mathrm{~mm}$-Quadrex), $\mathrm{T}_{\text {inlet }} 185^{\circ} \mathrm{C} ; \mathrm{T}_{\text {detector }} 300^{\circ} \mathrm{C}$; oven $90^{\circ} \mathrm{C}(1 \mathrm{~min}) 10^{\circ} \mathrm{C} / \mathrm{min} 360^{\circ} \mathrm{C}(7 \mathrm{~min})$ e vazão de 0,4 $\mathrm{mL} / \mathrm{min} \mathrm{H}_{2}$, com detector de ionização em chama (FID).

\section{Preparo das amostras para análise cromatográfica}

As amostras selecionadas foram submetidas a condições, devidamente controladas, de luminosidade e atmosfera de nitrogênio, oxigênio e ar por períodos que variaram de 1 a 15 dias. Os ensaios transcorreram sob temperatura variando de 29 a $32^{\circ} \mathrm{C}$ e umidade relativa de $45 \%$.

O conteúdo das cápsulas foi removido diretamente com o uso de solvente e agitação. As cápsulas foram abertas com o uso de bisturi e colocadas em tubo de ensaio contendo $5 \mathrm{~mL}$ de diclorometano. Outros $5 \mathrm{~mL}$ de diclorometano foram utilizados para a lavagem de resíduos no tubo de ensaio e para que a isotretinoína atingisse a concentração de $2 \mathrm{mg} \mathrm{mL}^{-1}$. A amostra foi acondicionada em frasco de vidro âmbar hermeticamente fechados para posterior análise por HRGC. 
Tabela 1. Quadro representativo das amostras de isotretinoína utilizadas nestes estudo

\begin{tabular}{c|l}
\hline Amostra & Descrição \\
\hline MP & Isotretinoína matéria-prima para indústria farmacêutica \\
\hline C1 & Cápsulas de gelatina mole, produto comercial de referência \\
\hline C2 & Cápsulas de gelatina mole, produto genérico \\
\hline C3 & Cápsulas de gelatina dura manipuladas em farmácia \\
\hline Padrão & Isotretinoína padrão USP 353500 \\
\hline
\end{tabular}

\section{RESULTADOS E DISCUSSÃO}

Nas figuras 1 e 2, é possível observar que o método proposto resulta em ótima definição do pico de isotrtetinoína, com excelente separação da tretinoína, que elui por volta de 9,7 minutos e que, segundo o fabricante da matéria-prima testada, estava presente em pequena concentração naquela amostra segundo laudo apresentado.

O estresse oxidativo ao qual foram submetidas as amostras teve o objetivo de acelerar a formação de subprodutos de degradação da isotretinoína para que fosse observada a capacidade do método proposto em separar e identificar tais produtos. Até então só haviam relatos do emprego da GC para caracterização da isotretinoína e seus produtos de degradação em amostras biológicas como demonstram os trabalhos de Chiang (1980), Oyler e colaboradores (1989), Lehman e Malany (1989) e Eckhoff e Nau (1990).

Na figura 3, observa-se que os produtos de degradação formados durante o período de oxidação da amostra eluem majoritariamente nos primeiros 10 minutos de corrida cromatográfica, enquanto que a isotretinoína elui aos 15 minutos, conforme demonstrado pelo cromatograma do padrão (fig 2) e cromatograma da matériaprima original (fig 3).

As formas farmacêuticas comerciais da isotretinoína (medicamentos genérico e referência) apresentam em sua composição excipientes de caráter graxo, particularmente ceras e óleos vegetais hidrogenados e não hidrogenados. Na figura 9, observa-se que as diversas frações do óleo eluem a partir de 17 minutos, sendo possível identificar as frações de mono, di e triacilglicerídeos.

Os cromatogramas das amostras dos medicamentos genérico e referência (figs 4, 5, 6 e 7) exibem uma clara diferença em relação ao perfil de eluição dos produtos de degradação da isotretinoína quando na ausência dos óleos. Observa-se um deslocamento dos picos referentes aos produtos de degradação provavelmente resultante de sua interação com os excipientes oleosos o que pode ser comprovado pela avaliação dos cromatogramas obtidos por injeção dos componentes oleosos contidos na amostra na presença e ausência do fármaco. Entretanto, a isotretinoína permanece com tempo de eluição de 15 minutos.

Esta observação é reforçada pela análise do cromatograma da cápsula de isotretinoína manipulada na ausência de excipientes oleosos (fig 10), o qual mostra perfil de eluição semelhante dos produtos de degradação observado com a matéria prima submetida ao estresse oxidativo (fig 3). 


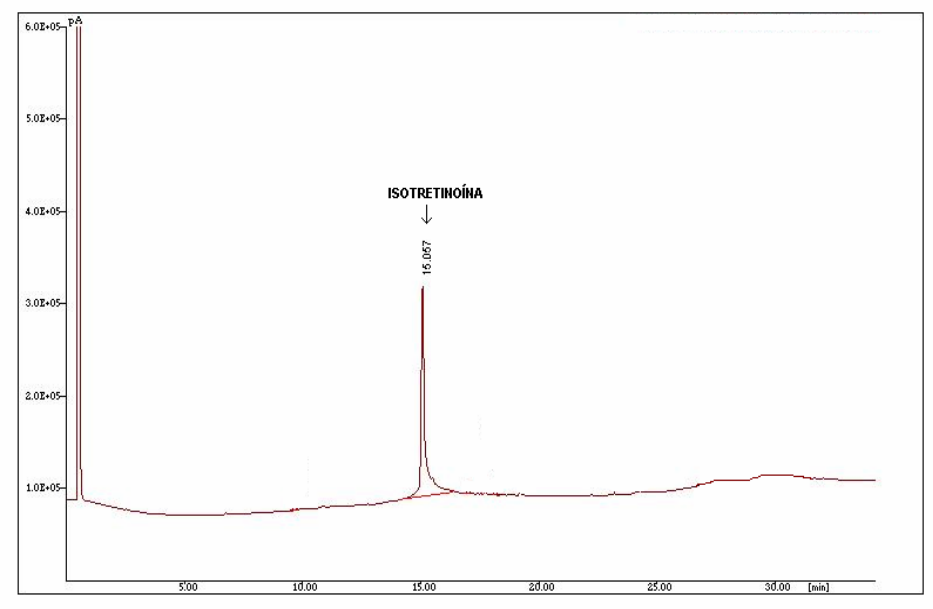

Fig 1. Cromatograma do padrão.

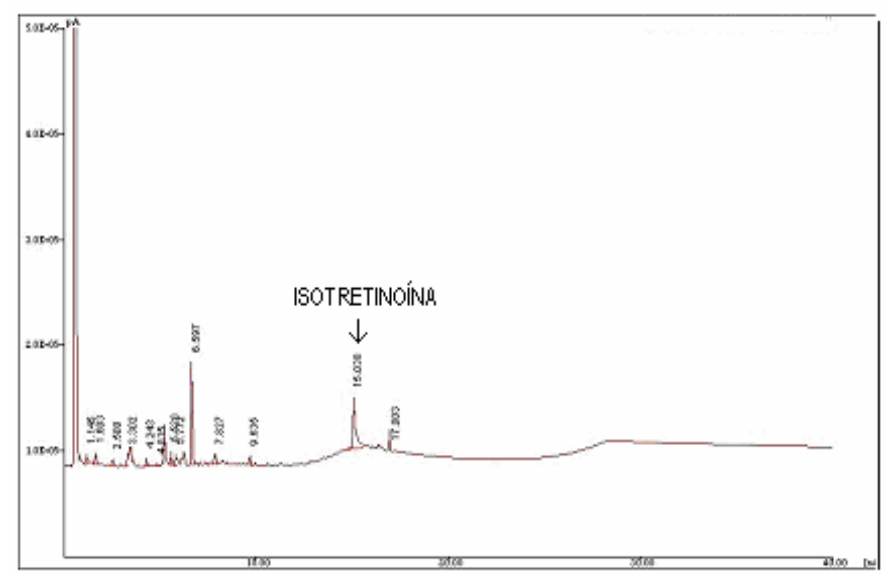

Fig 3. Cromatograma da amostra MP submetida a estresse oxidativo por 10 dias sob intensidade de luz de 1.200 LUX.

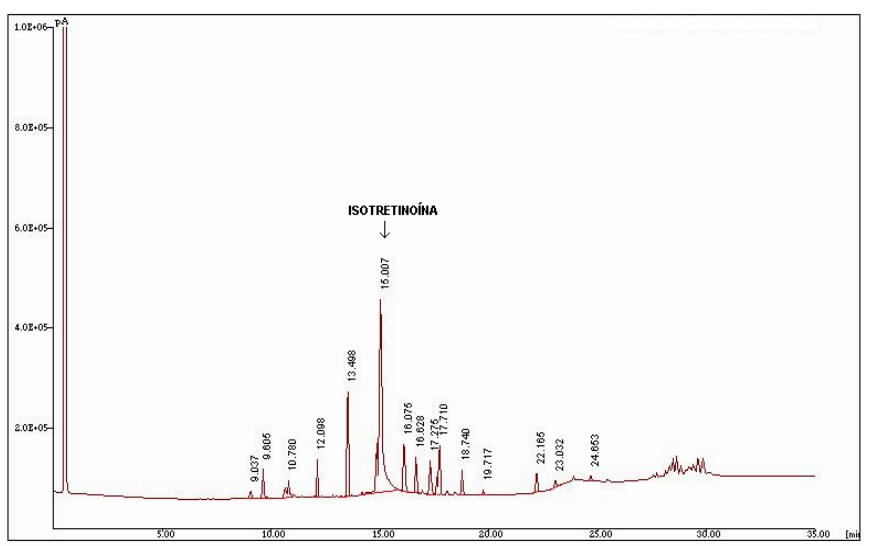

Fig 5. Cromatograma de amostra C1 submetida a estresse oxidativo por 10 dias sob intensidade de luz de 1.200 LUX.

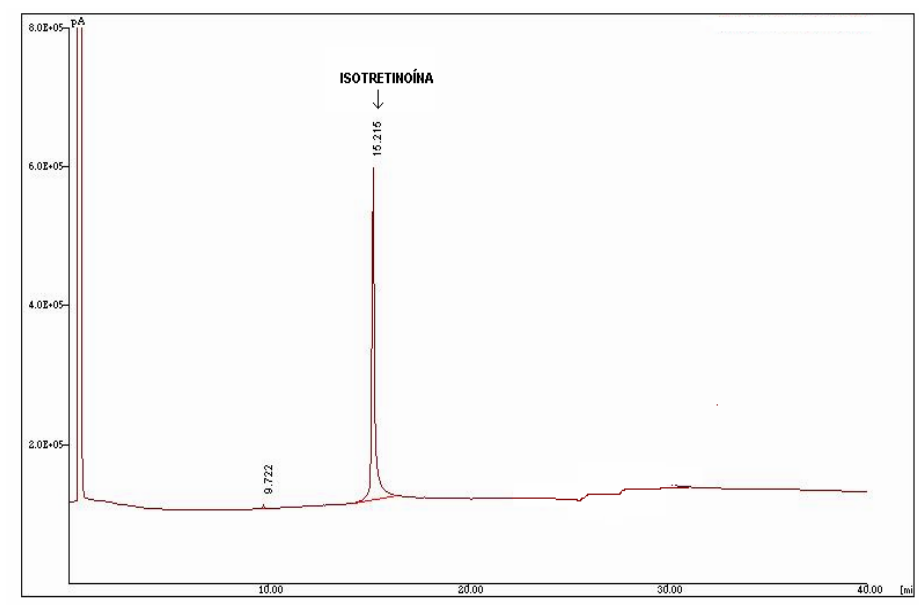

Fig 2. Cromatograma da amostra MP.

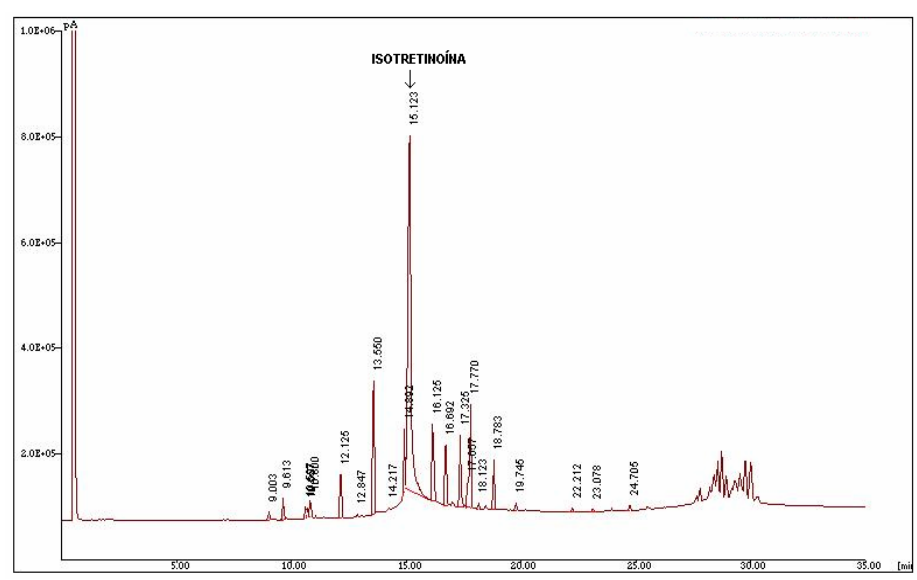

Fig 4. Cromatograma da amostra de medicamento de referência (C1).

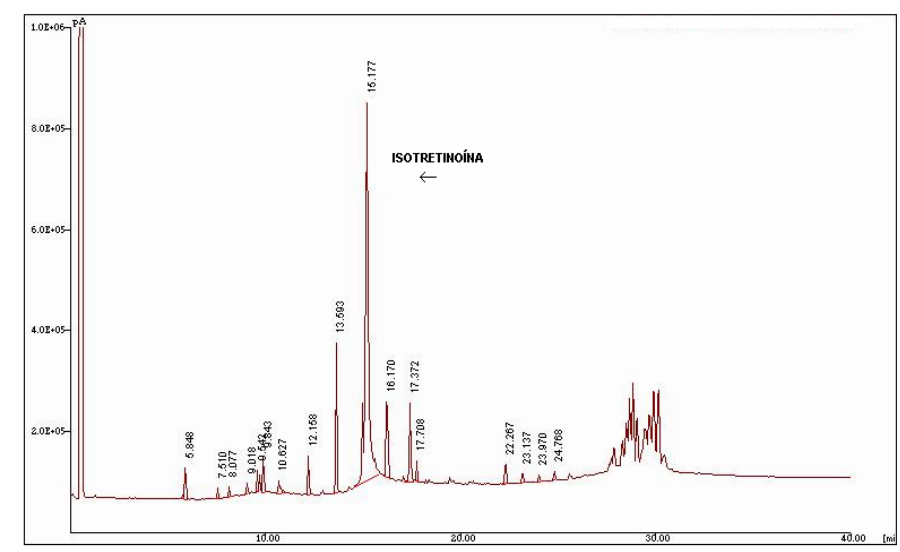

Fig 6. Cromatograma da amostra de medicamento genérico (C2). 


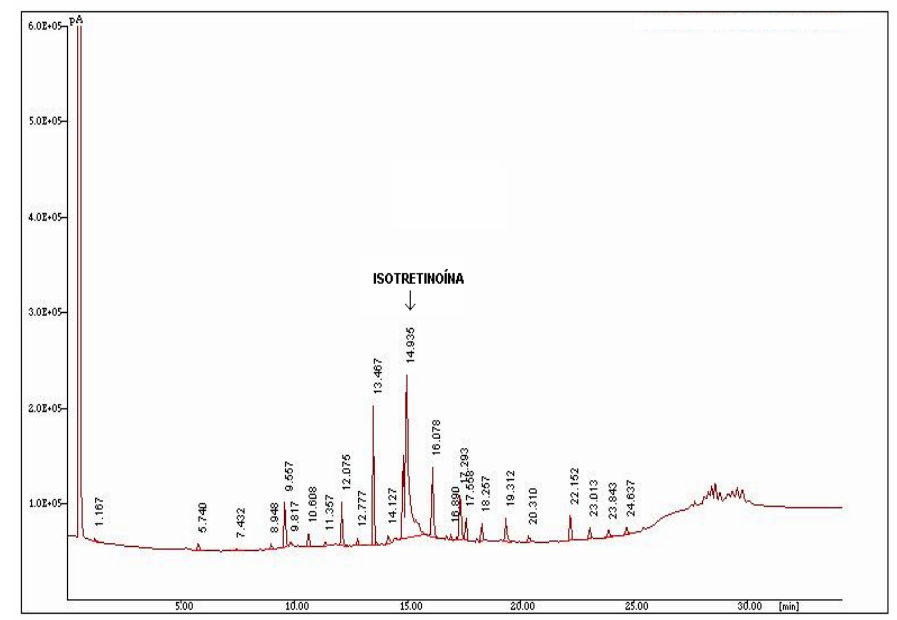

Fig 7. Cromatograma da amostra C2 submetida a estresse oxidativo por 10 dias sob intensidade de luz de 1.200 LUX.

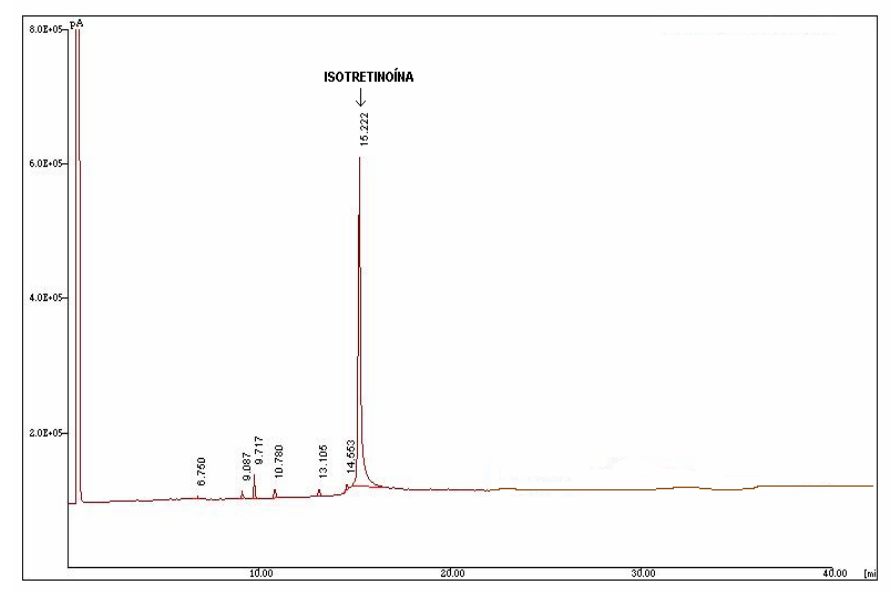

Fig 9. Cromatograma da amostra de cápsulas de gelatina dura manipuladas (C3).

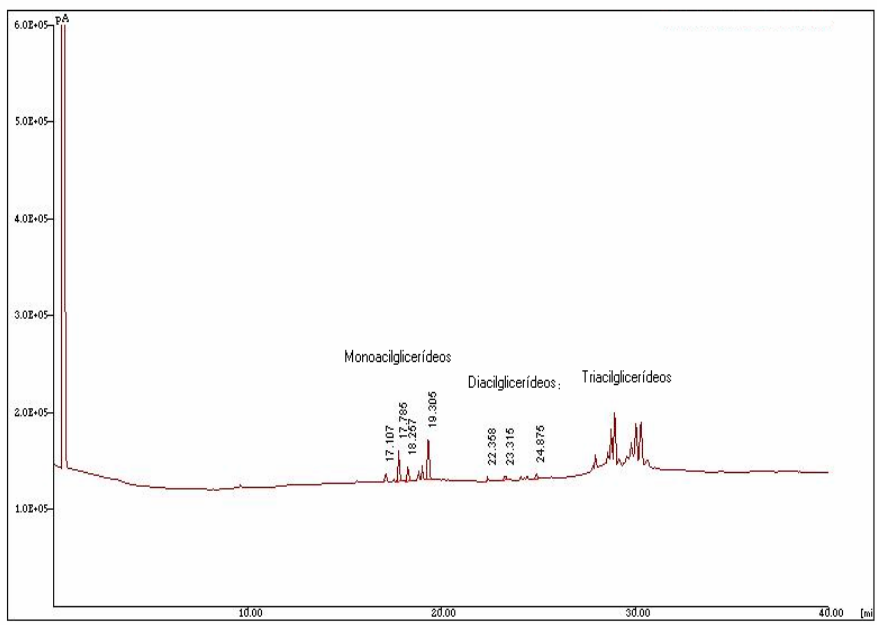

Fig 8. Cromatograma de amostra de óleo de soja, excipiente para indústria farmacêutica.

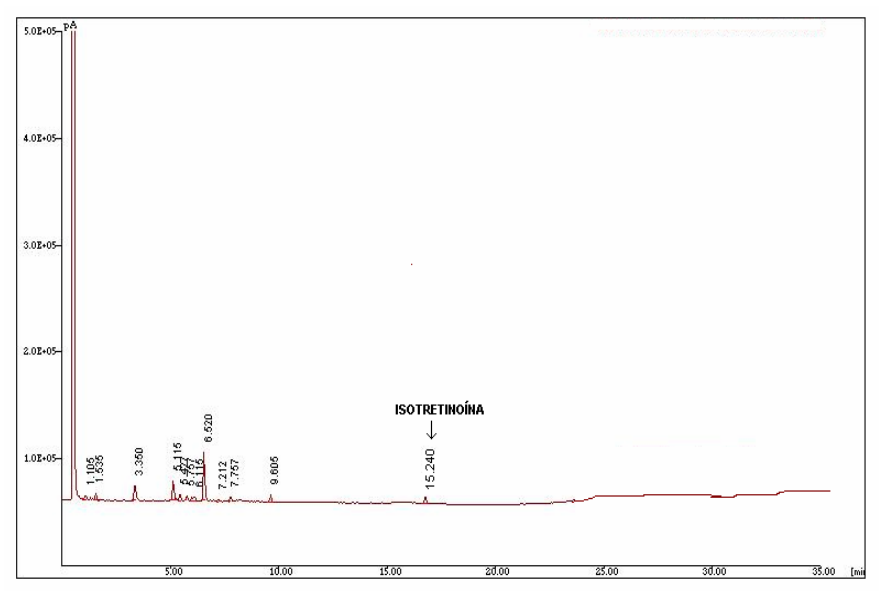

Fig 10. Cromatograma da amostra C3 submetida a estresse oxidativo por 10 dias sob intensidade de luz de 1.200 LUX

\section{CONCLUSÕES}

Este estudo teve como objetivo demonstrar o emprego da técnica de HRGC para identificação da isotretinoína e seus produtos de degradação em formas farmacêuticas. Os cromatogramas obtidos demonstram excelente desempenho na separação e definição dos picos da isotretinoína e seus sub-produtos de degradação com o emprego de colunas capilares de diâmetro interno e comprimento reduzidos e gás inerte para eluição dos compostos ao invés de solventes.

Os ensaios de estresse oxidativo sob condições forçadas de atmosfera e luminosidade foram responsáveis pela formação de grande número de subprodutos da isotretinoína, os quais puderam ser separados utilizando o método cromatográfico proposto. As amostras de medicamento de referência e genérico não permitiram visualizar o aparecimento destes subprodutos, os quais aparentemente já fazem parte da amostra mesmo antes de esta ser submetida ao estresse oxidativo. Este fato foi relacionado à presença de ceras e compostos oleosos parcialmente hidrogenados, além de outros excipientes que alteram as características de eluição. A realização de análise cromatográfica aplicando detector de massas para a identificação destes compostos de degradação parece ser a melhor alternativa neste caso, já que tanto para o medicamento de referência, quanto para o medicamento genérico foram observadas alterações nas propriedades físico-químicas da cápsula de gelatina mole.

A técnica de HPLC é ainda o método mais difundido para a análise dos retinóides. Entretanto o estudo do comportamento térmico da isotretinoína e a existência de trabalhos empregando cromatografia gasosa como técnica analítica para estudo de identificação de retinóides em matriz plasmática, permitiu desenvolver metodologia analítica utilizando GC para controle de qualidade de matéria-prima e produtos farmacêuticos contendo isotretinoína. 


\section{REFERÊNCIAS BIBLIOGRÁFICAS}

BRASIL. Consulta pública: ANVISA. Agência Nacional de Vigilância Sanitária. Consulta de produtos de empresas de medicamento. Disponível em:< http://www.anvisa.gov.br>. Acesso em: Jan. 2003

BREITMAN, T. R.; COLLINS, S.J.; KEENE, B,R. Terminal differentiation of human promyelocytic leukemia cells in primary culture in response to retinoic acid. Blood., New York, v. 57, n. 6, p. 1000-1004, 1981.

CHANDRARATNA, R. A. S. Tazarotene, first of a new generation of receptor selective retinoids. Br. J. Dermatol., Oxford, v. 135, n. Suppl 49, p. 18s-25s, 1996.

CHIANG, CHING-TEH. Gas chromatographic - mass spectrometric assay for low levels of retinoic acid in human blood. J. Chromatogr., Amsterdam, Amsterdam, v. 182, n. 3-4 , p. 335-340, 1980.

DINIZ, D.G.A.; LIMA, E.M.; FILHO, N.R.A. Isotretinoína: perfil farmacológico, farmacocinético e analítico. Revista Brasileira de Ciências Farmacêuticas. v. 38, p. 415-430, 2002.

ECKHOFF, C.; NAU, H. Identification and quantitation of all-trans- and 13-cis-retinoic acid and 13-cis-4-oxoretinoic acid in human plasma. J.Lipid. Res., Bethesda, v.31, n.8, p. 1445-1454, 1990.

ELLIS, C.N.; KRACH, K.J. Uses and complications of isotretinoin therapy. J. Am. Acad Dermatol. v. 45, p. S150157, 2001.

FDA (U. S. Food and Drug Administration ) - FDA Oncology Tools Approval Summary for tretinoína, ATRA for induction of remission in patients with acute promyelocitic leukemia(APL) who are refractory to or unable to tolerate anthracycline based cytotoxic chemotherapeutic regimes. Disponível em: <http://www.acessdata.fda.gov/scripts/cder>. Acesso em: agosto 2002

GATTI, R.; GIOIA, M.G.; CAVRINI, V. Analysis and stability study of retinoids in pharmaceuticals by fluorescence detection. J. Pharm. Biomed. Anal., Oxford, v.23, n. 1, p. 147-159, 2000.

GUNDERSEN, TH. E.; LUNDANES, E.; BLOMHOFF, R. Quantitative high-performance liquid chromatographic determination of retinoids in human serum using on-line solid-phase extraction and column switching.

Determination of 9-cis-retinoic acid, 13-cis-retinoic acid, all-trans-retinoic acid, 4-oxo-all-trans-retinoic acid and 4oxo-13-cis-retinoic acid. J. Chromatogr. B., Amsterdam, v. 691, n. 1, p. 43-58, 1997.

GUNDERSEN, Th. E.; BLOMHOFF, R. Qualitative and quantitative liquid chromatography determination of natural retinoids in biological sample. J.Chromatogr. A., Amsterdam, v. 935, n. 1-2, p. 13-43, 2001.

HARISIADIS, L. R.; MILLER, R.C.; HALL, E.J.; BOREK, C., A vitamina A analog inhibits radiation-induce oncogenic transformation. Nature, London , v. 274, n. 3, p. 486-487, 1978.

LEHMAN, P.A. ; MALANY, A. M. Evidence for percutaneous absorption of isotretinoin from the photo- isomerization of topical tretinoin. The J. Invest. Dermatol., Baltimore, v. 93,n.5, p.595-599, 1989.

LOTAN, R. Effects of vitamin A and its analogs (retinoids) on normal and neoplastic cells. Biochem. Biophys. Acta., Amsterdam, v. 605, n. 1, p. 33-91, 1980.

LOTAN, R.; ONG, D. E.; CHYTIL, F. Comparison of the level of cellular retinoic-binding proteins and susceptibility to retinoid induced growth inhibition of various neoplastic cell lines. J. Natl. Cancer. Inst., Bethesda, v. 64, n. 5, p. 1259-1262, 1980.

NAGPAL, S.; ATHANIKAR, J.; CHANDRARATNA, R.S.A. Separation of trans-activation and AP1 antagonism functions of retinoic acid receptor $\alpha$. J.Biol.Chem., Berlin, v.270, n.,p.923-927, 1995.

OYLER, A. R.; MOTTO, M.G.; NALDI, R.E.; FACCHINE, K.L.; HAMBURG, P.F.; BURINSKY, D.J.; DUNPHY, R.; COTTER, M.L. Characterization of autoxidation products of retinoic acid. Tetrahedron., Oxford, v. 45, n. 24, p. 7679-694, 1989.

SPORN, M.B.; DUNLOP, N.M.; NEWTON, D.L.; SMITH, J.M. Prevention of chemical carcinogenesis by vitamina A and its synthetic analogs (retinoids). Federation Proceedings., Bethesda, v. 35, n. 6, p. 1332-1338,1976.

SPORN, M.B; ROBERTS, A.B. What is a retinoid? In-Retinoids differentiation and disease. Ciba Found Symp. v.113, p. 1-5, 1985. 